\title{
The nature of the semantic stimulus: the acquisition of every as a case study
}

\author{
Ezer Rasin ${ }^{1,2}$ (D) Athulya Aravind 3 \\ Published online: 15 December 2020 \\ (c) The Author(s) 2020, corrected publication 2021
}

\begin{abstract}
We evaluate the richness of the child's input in semantics and its relation to the hypothesis space available to the child. Our case study is the acquisition of the universal quantifier every. We report two main findings regarding the acquisition of every on the basis of a corpus study of child-directed and child-ambient speech. Our first finding is that the input in semantics (as opposed to the input in syntax or phonology) is rich enough to systematically eliminate instances of the subset problem of language acquisition: overly general hypotheses about the meaning of every can violate pragmatic constraints, making such hypotheses incompatible with the child's input. Our second finding is that the semantic input is too poor to eliminate instances of what we refer to as the superset problem, the mirror image of the subset problem. We argue that at least some overly specific hypotheses about the meaning of every are compatible with the child's input, suggesting either that those hypotheses are not made available by UG or that non-trivial inductive biases are involved in children's acquisition of every.
\end{abstract}

Keywords Acquisition · Quantifiers · Corpus

For helpful feedback and discussion, we are grateful to Christine Bartels, Itai Bassi, Brian Buccola, Kai von Fintel, Martin Hack1, Aron Hirsch, Loes Koring, Fred Landman, Daniel Margulis, David Pesetsky, Roger Schwarzschild, the audiences at MIT and CNRS Paris, and especially Danny Fox, Irene Heim, and Roni Katzir.

$\bowtie \quad$ Ezer Rasin

rasin@tauex.tau.ac.il

Athulya Aravind

aaravind@mit.edu

1 Leipzig University, Leipzig, Germany

2 Tel Aviv University, Tel Aviv, Israel

3 MIT, Cambridge, MA, USA 


\section{Introduction}

As part of language acquisition, the child needs to make sense of unanalyzed input: she brings to the task a space of possible grammars, and she chooses a grammar in that space that can generate the input. If two conceivable grammars $G, G^{\prime}$ can generate the input and the child ends up selecting $G$, we can draw interesting conclusions regarding learning. It could be, for example, that $G^{\prime}$ is outside of the child's hypothesis space, or that the child is biased towards choosing $G$ over $G^{\prime}$. The literature on acquisition in syntax and phonology has identified cases where multiple grammars can generate the input, suggesting that learning in those domains is non-trivial.

Consider, for example, the so-called that-trace effects in English discovered by Perlmutter (1971) and discussed in the context of acquisition by Chomsky and Lasnik (1977). A wh-question in English can be formed by extracting an object out of an embedded clause regardless of whether the complementizer that is pronounced (1), while subject extraction is only possible without a pronounced complementizer (2).

(1) Object extraction is possible with or without an overt complementizer:

a. Who do you think Michelle met _ ?

b. Who do you think that Michelle met _ ?

(2) Subject extraction is only possible without an overt complementizer:

a. Who do you think _ met Michelle?

b. *Who do you think that _ met Michelle?

Negative evidence directly informing the English-learning child that (2b) is not part of the language is unavailable. Nevertheless, the child prefers a grammar that does not generate (2b) over a more permissive grammar $G^{\prime}$ that does generate it, given in (3). This is an instance of the so-called subset problem of language acquisition. Other instances of the subset problem have been discussed by Dell (1981), Berwick (1985), Wexler and Manzini (1987), Crain et al. (1994), and Prince and Tesar (2004), among others.

(3) a. $G=$ the grammar of English

b. $G^{\prime}=$ a grammar that generates $(2 \mathrm{~b})$ in addition to whatever $G$ generates

This instance of the subset problem could suggest, for example, that $G^{\prime}$ is not part of the hypothesis space (at least before we consider the behavior of that-trace effects in other languages). Alternatively, if both $G$ and $G^{\prime}$ are in the child's hypothesis space, this instance of the subset problem would teach us that the null theory of language acquisition - according to which learning is trivial and involves no induction-is incorrect. A version of this null theory is given in (4). It presupposes that there is exactly one grammar in the hypothesis space that is compatible with the child's input, and it states that the child simply selects that grammar (here and below we will say that a grammar or a hypothesis are "compatible" with the input if they can generate the input). 
(4) Null theory of language acquisition (to be updated below in (16)):

The child selects the (only) hypothesis compatible with the input

If both $G$ and $G^{\prime}$ are in the child's hypothesis space, the null theory would not be able to explain why the child selects $G$ over $G^{\prime}$. More generally, the null theory fails whenever two grammars in the hypothesis space are compatible with the input. Instead, the fact that the child selects $G$ in the face of an available alternative would support a more complex theory of language acquisition where some learning principle guides the learner towards $G$ over the more permissive $G^{\prime}$. Since (4) is a simple-in fact, trivial - theory of language acquisition, rejecting it in favor of a more complex theory would be an interesting discovery about language acquisition.

Here is another syntactic example from English, which presents the mirror image of the subset problem. English $w h$-questions can be formed by extracting direct objects out of unboundedly many embedded clauses, as illustrated in (5a,5b). The child never hears questions like (5b), in which an object has been extracted out of multiple embedded clauses (at least not beyond a certain degree of embedding, which for the sake of discussion we will assume is two). Nevertheless, adult speakers judge sentences like (5b) as grammatical.

(5) Object extraction is possible out of unboundedly many embedded clauses:

a. Who do you think that Michelle met _ ?

b. Who do you think that Michelle said that Bill believes that John met ?

In this case, the English-learning child draws a generalization and converges on a grammar that is more permissive than a conceivable alternative: a grammar $G^{\prime}$ that only allows extraction out of a limited number of embedded clauses, given in (6). This state of affairs could teach us that $G^{\prime}$ is not part of the hypothesis space. Alternatively, it could teach us that the null theory of language acquisition in (4) is incorrect; instead, the correct theory of acquisition includes a learning principle that biases the child in favor of the grammar of English, over the grammar $G^{\prime}$ which generates fewer sentences. We will refer to the problem of converging on a more permissive grammar as the superset problem of acquisition, to highlight the symmetry between this problem and the more familiar subset problem.

(6) a. $G=$ the grammar of English

b. $G^{\prime}=$ a grammar that can generate whatever $G$ generates except for sentences with object extraction out of more than two embedded clauses

In this paper we will construct and evaluate candidates for similar learning problems in semantics and discuss their implications for the hypothesis space and for the null theory of acquisition in (4) as a potential theory of semantic acquisition. Our case study is the acquisition of the universal quantifier every. As we will see, acquiring the meaning of every faces a version of the subset problem whenever alternative meanings that are logically weaker than the universal quantifier would be compatible with the input. By contrast, alternative meanings that are logically stronger pose a version of the superset problem. 
Consider first a simple candidate for a subset problem in the acquisition of every, introduced by Piantadosi et al. (2012). To simplify the discussion, we will assume that the adult's meaning of every is the one in (7): a function that takes two sets as

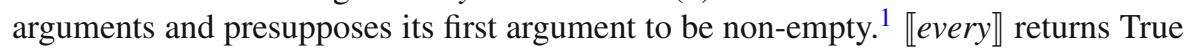
if the first argument (the restrictor) is a subset of the second argument (the scope). Consider also the alternative denotation for every in (8) - the set representation of the existential quantifier-which takes two sets and returns True if their intersection is non-empty. We will refer to this alternative as «every $\exists \rrbracket$.

(7) $\llbracket$ every $\rrbracket=\lambda P:|P|>0 . \lambda Q \cdot P \subseteq Q$

(8) $\llbracket$ every $\rrbracket \rrbracket=\lambda P . \lambda Q . P \cap Q \neq \emptyset \quad(=\llbracket$ some $\rrbracket)$

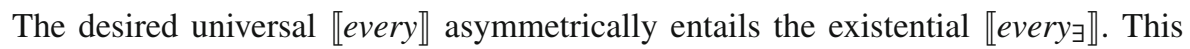
means that in many contexts, the usage of the universal quantifier by an adult would be consistent with the existential meaning, but not the other way around, as illustrated by (9)-(10).

(9) Context: Five out of five girls ran.
a. Every girl ran. (True)
b. Some girl ran. (True)

(10) Context: Three out of five girls ran.
a. Some girl ran. (True)
b. Every girl ran. (False)

For the child acquiring the meaning of the English word every, the challenge would be to converge on a meaning whose extension is a subset of that of an alternative meaning:

(11) A potential subset problem in the acquisition of every: ${ }^{2}$ $\llbracket$ every $\subset \llbracket$ every $\exists \rrbracket$

If $\llbracket e v e r y_{\exists} \rrbracket$ is compatible with the input available to the English-learning child, the

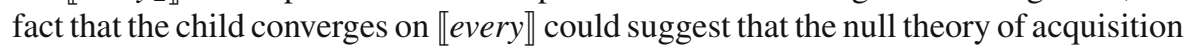
in (4) is not the right theory of quantifier learning, and that the child is instead biased

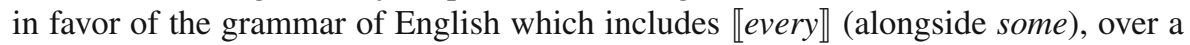
grammar $G^{\prime}$ that includes «every $\exists \rrbracket$ :

a. $G=$ the grammar of English:

$$
\begin{aligned}
& \text { - } \llbracket \text { some } \rrbracket=\lambda P . \lambda Q . P \cap Q \neq \emptyset \\
& \text { - } \llbracket \text { every } \rrbracket=\lambda P: P \neq \emptyset . \lambda Q . P \subseteq Q \\
& \text { - } \quad \cdots
\end{aligned}
$$

\footnotetext{
${ }^{1}$ Our assumption that the denotation of every includes the $|P|>0$ presupposition is meant to simplify the discussion throughout the paper by allowing us to talk about entailment between the universal quantifier and the existential quantifier. We note, however, that there have been arguments to the contrary (Landman 2004, p. 27). As far as we can tell, our conclusions in this paper would not change if this presupposition is removed.

${ }^{2}$ Here and below we use $\llbracket Q_{1} \rrbracket \subset \llbracket Q_{2} \rrbracket$ as shorthand for $\forall P . \llbracket Q_{1} \rrbracket(P) \subset \llbracket Q_{2} \rrbracket(P)$.
} 
b. $G^{\prime}=$

- $\llbracket$ some $\rrbracket=\lambda P . \lambda Q . P \cap Q \neq \emptyset$

- $\llbracket$ every $\rrbracket \rrbracket=\lambda P \cdot \lambda Q . P \cap Q \neq \varnothing$

- ...

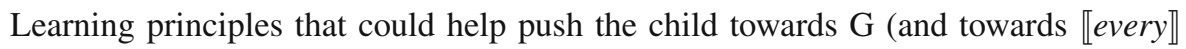
over $\llbracket$ ever $\left.y_{\exists} \rrbracket\right)$ have been previously proposed in the literature on semantic learning. They include the Principle of Contrast (Clark 1987), the Semantic Subset Principle (Crain et al. 1994), the likelihood component of Bayesian learning (Piantadosi et al. 2012, 2016), and the $|D: G|$ component of Minimum Description Length (Katzir et al. 2020). If it turns out that «every $\exists \rrbracket$ is not compatible with the child's input, the subset problem would not arise in this case and the null theory of acquisition in (4) could be maintained as a theory of quantifier learning without the complication of additional principles. $^{3}$

Does the subset problem indeed arise in this case and support the rejection of (4) in favor of a theory with additional learning principles? The answer depends on whether «every $\exists \rrbracket$ is in fact consistent with usages of every in the child's input. In our discussion above of the subset problem in syntax, we mentioned that parents do not tend to correct their children for grammaticality, making both the English grammar and a more permissive alternative compatible with the input. It has already been pointed out, however, that the input in semantics is quite different from the input in syntax. For example, while parents do not tend to correct their children for grammaticality, they do object to false statements made by children (Brown and Hanlon 1970). Direct objections are one kind of input that can provide the child with direct evidence against 【every $y_{\exists} \rrbracket$, but it remains an open question whether relevant objections or other kinds of informative input for quantifier learning are systematically available to the child.

We address this question in Sect. 3, where we examine whether the semantic input is rich enough to rule out $\llbracket$ every $y_{\exists} \rrbracket$ as an alternative to $\llbracket$ every $\rrbracket$ and eliminate this instance of the subset problem. We will first consider truth-conditional evidence that can rule

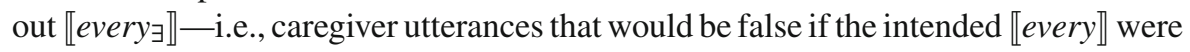
replaced with «every $\exists \rrbracket$ — and conclude that such evidence is not systematically present in the child's input. Importantly, however, we will show that pragmatic input changes the picture. Our main finding reported in Sect. 3 is that the child is systematically exposed to utterances that would violate some pragmatic constraint on the assumption that every has the existential meaning but not on the assumption that it has the universal meaning. An example is the question in (13a), uttered in a context where a variant of the question with an existential quantifier would be odd (this example and others will be discussed in more detail in Sect. 3). If the child is able to use such input to conclude that «every $\exists \rrbracket$ is an inappropriate meaning for every, no special learning principles

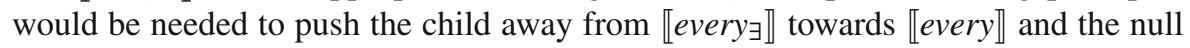
theory of acquisition in (4) would be sufficient in this case.

\footnotetext{
3 Additional learning principles have been proposed for other learning problems in semantics; see, for example, Markman (1990), Landau et al. (1988), Markman et al. (2003), and Xu and Tenenbaum (2007). In this paper we focus on the problem of quantifier learning and leave aside other learning problems and their consequences for theories of learning.
} 
(13) Context: somebody has arrived.

a. Is everybody here?

b. \#Is anybody here?

After discussing the subset problem in Sect. 3, we turn to the superset problem in Sect. 4. An example of a potential superset problem in the acquisition of every is provided by the quantifier in (14). This quantifier is a variant of the universal quantifier with a stronger presupposition: it requires its restrictor to have a cardinality greater than 2 (rather than just be non-empty).

$$
\llbracket \text { every }_{>2} \rrbracket=\lambda P:|P|>2 . \lambda Q \cdot P \subseteq Q
$$

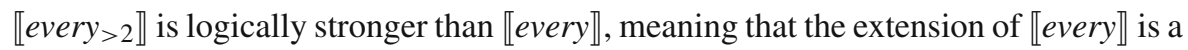

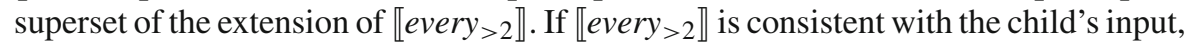
we have an instance of the superset problem of acquisition, since the English-learning

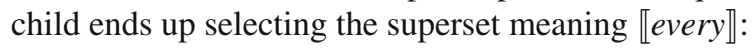

(15) A potential superset problem in the acquisition of every: $\llbracket$ every $>2 \rrbracket \subset \llbracket$ every $\rrbracket$

After examining the English-learning child's input, our main finding reported in Sect. 4 is that there is no systematic evidence against quantifiers like $\llbracket$ every $>2 \rrbracket$ as a meaning for every, posing a superset problem of induction for the English-learning child. This problem suggests either that the hypothesis space for quantifier meanings excludes quantifiers like $\llbracket$ every $>2 \rrbracket$ or that non-trivial inductive biases are involved in children's

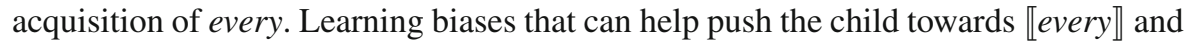
away from «every $>2 \rrbracket$ have been previously proposed for quantifier learning. They include the simplicity-prior component of Bayesian learning (Piantadosi et al. 2012, 2016) and the $|G|$ component of Minimum Description Length (Katzir et al. 2020).

Before we turn to describing our general methodology in Sect. 2, a note on previous related research. To our knowledge, there has been little work on the nature of the stimulus in formal semantics, and the work that does exist has focused on learning problems that are quite different from the ones we are interested in here. In particular, we know of no prior work on the relationship between the semantic stimulus and the hypothesis space for quantifier meanings. Crain et al. (1994) and Gualmini and Schwarz (2009) discuss the evidence available to the child in the process of deciding between multiple interpretations of ambiguous quantificational statements (rather than the process of acquiring lexical entries for quantifiers). The literature on syntactic bootstrapping (Gleitman 1990 et seq.) has focused on word-learning problems in which syntactic context can provide helpful evidence for the child when deciding between competing hypotheses. The learning problems we discuss in this paper are meaningfully different in that they all involve choices between competitors for which the syntax is fixed (for example, syntactic context cannot help decide between «every》 and $\llbracket$ every $>2 \rrbracket$ since the two would have an identical syntactic distribution).

More closely related to our goals in this paper, Hacquard and Lidz (2019) discuss the evidence available to the child when acquiring the meaning of attitude predicates like think and want. They propose that in addition to syntactic context, the child's ability to 
understand speakers' intended speech acts (e.g., identify a request) can help the child to learn the meaning of attitude predicates. Differently from the problems discussed by Hacquard and Lidz, such abilities will not help the child in the cases we consider. Similarly to Hacquard and Lidz, however, we will conclude that pragmatic evidence can play an important role in semantic acquisition (specifically, general pragmatic reasoning can help eliminate certain instances of the subset problem presented by the child's input).

\section{General methodology}

To investigate whether the child's input contains negative evidence against competing hypotheses about the meaning of every, we used the Manchester corpus in CHILDES (Theakston et al. 2001; MacWhinney 2000). The Manchester corpus consists of transcripts of audio recordings from 12 British-English-speaking children, collected over a period of one year. Children were roughly two years old at the beginning of the study and three years old at the end. The transcripts record conversations during normal play activities between the children and their mothers.

We extracted all tokens of every in child-directed and child-ambient speech as well as child speech and examined each utterance with every in context (up to 50 lines of preceding discourse and 5 following). ${ }^{4}$ We included occurrences of every as parts of other words, such as everything, everyone, and everybody, on the assumption that these are complex words which contain the lexical item every, and we excluded occurrences of quantifiers like all and each, on the assumption that these are distinct lexical items whose denotation needs to be learned separately. We coded each child utterance with every for whether the use of every elicited explicit negative feedback from the caregiver. We coded each caregiver utterance with every for whether it contributes negative evidence of two types - truth-conditional evidence and pragmatic evidence-according to specific criteria that will be described in more detail in the following sections. All utterances were coded independently by the two authors, with inter-coder reliability established to be above 90\% (Cohen's Kappa > 0.90).

Figures 1 and 2 show the frequency of every relative to the total number of words produced by each speaker per corpus. The y-axes show relative frequency per thousand words. As the figures make plain, across corpora, every was infrequent in both caregiver speech (746 out of 339,713 utterances overall) and child speech (72 out of 224,795 utterances overall). Given that the spontaneous speech samples in the corpus represent only around 1-2\% of the language the child hears and produces during the sampling period, the question arises whether the findings from the sample are in fact true to the child's actual experience (see Tomasello and Stahl 2004 for discussion). Throughout the paper we will assume that the sample size for parent speech is big enough to make the corpus representative in terms of the frequency of occurrences. We provide binomial-proportion confidence intervals along with our reported frequencies

\footnotetext{
4 As is standard, we exclude from the counts full or partial repetitions and clearly rote or formulaic expressions.
} 


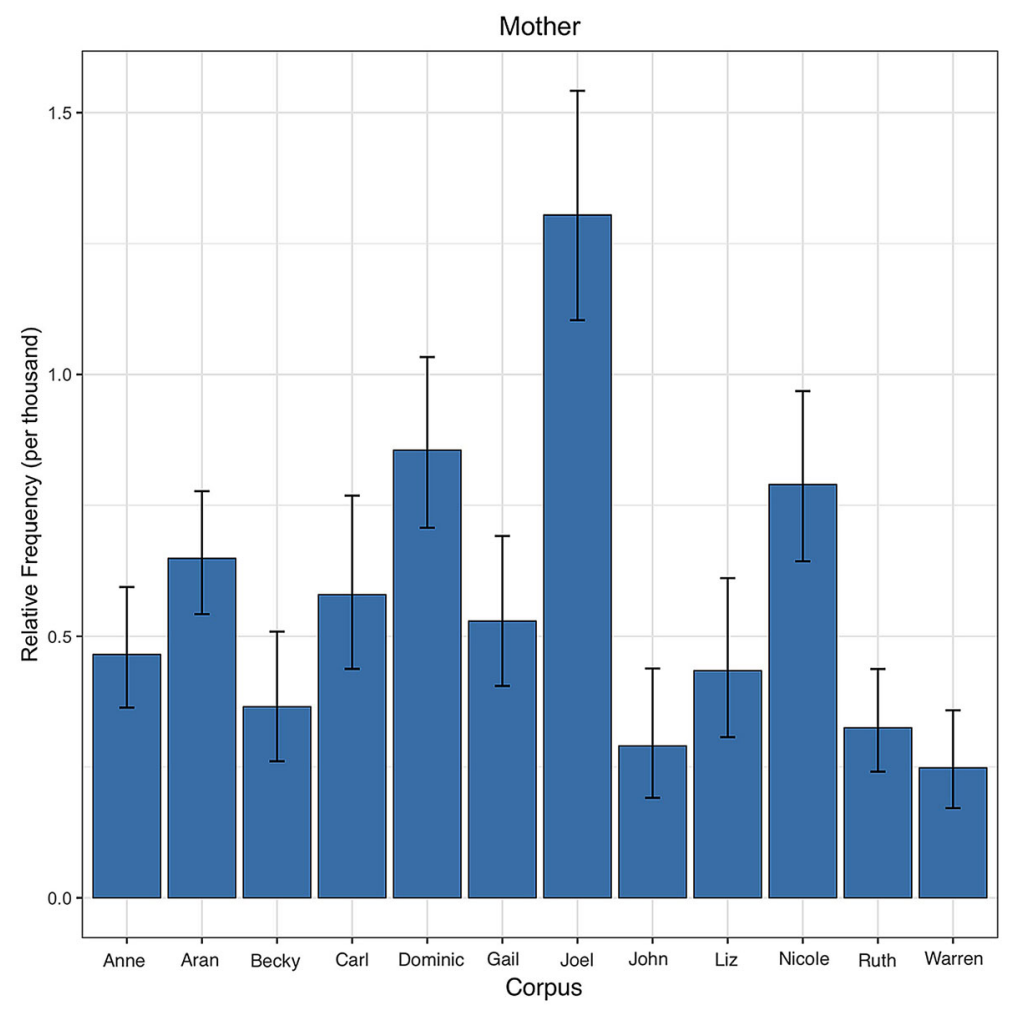

Fig. 1 The relative frequency of every in the speech of mothers in the Manchester corpus. 95\% binomial proportion confidence intervals calculated using the Agresti-Coull's approximate method

to support this assumption. ${ }^{5}$ The conclusions to be drawn from child speech are more limited as the relevant occurrences are extremely sparse.

Our starting point for evaluating the availability of negative evidence against competing meanings for every was the null theory of learning in (4). This theory is an idealization which ignores issues like the presence of noise in the input, i.e., ungrammatical utterances made by the caregivers. As noted by Marcus (1993), if the input includes some amount of noise, the learner must be able to select grammars that are inconsistent with a small percentage of the input, so in order for negative evidence to be informative for the child it has to be systematically available. Suppose, for example, that the learner can simply ignore $2 \%$ of the input as noise. Then a slight modification of the null theory which deals with noise will be as follows: ${ }^{6}$

\footnotetext{
${ }^{5}$ Unless otherwise specified, these are 95\% confidence intervals calculated using the Agresti-Coull's approximate method.

6 This formulation of the null hypothesis raises important questions that we will leave aside to keep the discussion simple, such as whether the entire grammar has to be compatible with at least $n \%$ of the input or whether just a certain property of the grammar (e.g., the meaning of every) has to be compatible with at least $n \%$ of a certain portion of the input.
} 


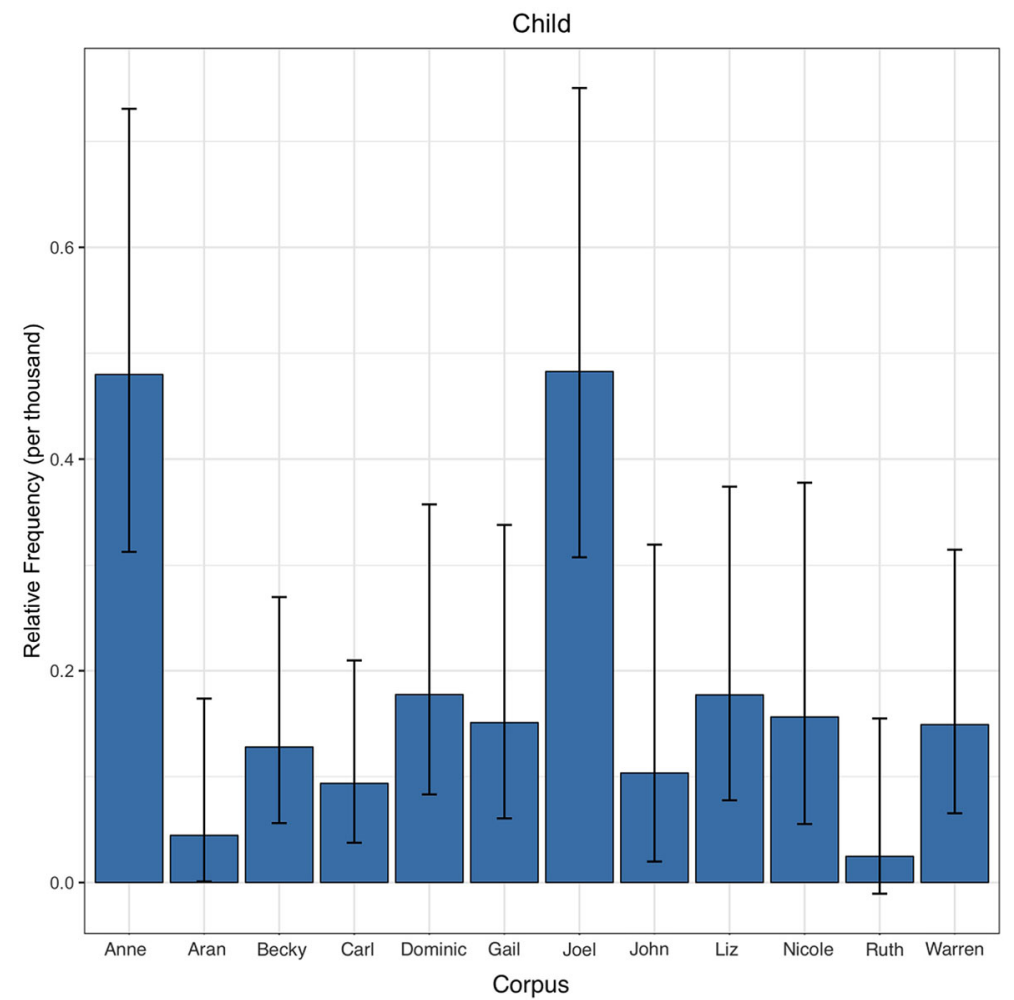

Fig. 2 The relative frequency of every in the speech of children in the Manchester corpus. 95\% binomial proportion confidence intervals calculated using the Agresti-Coull's approximate method

(16) Null theory of language acquisition (updated from (4))

a. The child selects the (only) hypothesis compatible with at least $n \%$ of the input.

b. $n=98$.

The theory of language acquisition in (16) remains a simple, idealized, and trivial theory that says that language acquisition involves no real induction but rather simply a selection of the single hypothesis compatible with the evidence, modulo some noise. Evidence against this theory, as has been found in syntax and phonology, would constitute meaningful progress in our understanding of language acquisition in the domain of quantifier learning. Exactly how much noise the child can ignore, i.e. exactly what percentage of the evidence counts as systematic is an open and interesting question that we will have nothing to say about in this paper. Instead, our goal will be to evaluate the null theory of language acquisition in (16) as a theory of acquisition in the domain of quantifier learning, assuming the number $98 \%$ as a rough approximation, i.e., assuming that negative evidence for ruling out an hypothesis must constitute more than $2 \%$ of the input. In the remainder of this paper, whenever we discuss the systematicity of negative evidence and its ability to rule out competing hypotheses about the 
meaning of every, we will be assuming the theory in (16). The conclusions that we draw in the following sections do not rely on the precise number $2 \%$. In particular, the one case of negative evidence we considered to be systematic concerned $17.5 \%$ (131/746) informative utterances with negative evidence, and the three cases of negative evidence we considered to be non-systematic concerned $1.75 \%$ (13/746) or less of the utterances (we will discuss these numbers again in the context of our specific findings). Of course, the significance of our conclusions will be low if future research discovers that children require different amounts of negative evidence to rule out the alternative hypotheses about the meaning of every that we will consider.

\section{Logically weaker alternatives and the subset problem}

In this section we address the question of whether an existential meaning for the English word every is systematically incompatible with usages of every in the child's input. We start, in Sect. 3.1, by asking whether caregivers provide explicit negative feedback to children's incorrect uses of every. Having shown that such cases are vanishingly rare, in Sect. 3.2 we focus on the truth-conditional content of caregiver utterances, leaving pragmatic reasoning aside. We consider several potential sources of truthconditional evidence that could provide the child with evidence against the existential meaning, including downward-entailing environments, non-monotonic environments, and various environments where the existential quantifier cannot be used. In each case, we ask whether replacing the universal meaning of every with an existential meaning in a given utterance results in a false utterance or in a violation of some semantic constraint. If it does, we consider the utterance to be informative, i.e., we consider it to provide the child with direct evidence against the existential meaning. Our conclusion in Sect. 3.2 will be that while some of these sources do exist in the input, they do not provide systematic evidence against the existential meaning. We then proceed to examine the contribution of pragmatics in Sect. 3.3. We show that once familiar pragmatic principles are taken into consideration, a meaningful portion of the usages of every in the child's input would have been odd if every had an existential meaning. If the child is able to reason pragmatically about such input before having acquired the meaning of every, she can eliminate the existential hypothesis for every without special learning principles, in accordance with the null theory of language acquisition in (16).

\subsection{Explicit negative feedback}

On the basis of an analysis of child-parent interactions, Brown and Hanlon (1970) reported that parents object to around $25 \%$ of false statements made by children. A direct objection to a child's utterance could provide explicit evidence against weaker meaning candidates for a quantifier. Consider the hypothetical exchange in (17). In this exchange, the child makes a statement that is false under a universal meaning for every but not under the weaker existential meaning. On the assumption that interlocutors speak truthfully, the parent's objection would be nonsensical if every were 
an existential. Given such an exchange, the child could conclude that every does not have an existential meaning.

(17) Scenario: A family expects three guests for dinner: Michelle, John, and Sue. Michelle has arrived on time, but John and Sue are late.

a. Child: Every guest is here.

b. Parent: No. Only Michelle is here. John and Sue are not here.

The potential informativeness of direct objection with respect to the subset problem is general. Since stronger quantifier meanings can lead to stronger statements, a child using a word with a stronger meaning than a conceivable alternative might make statements that are too strong to be true. If parents systematically object to children's false utterances, as reported by Brown and Hanlon, direct objection is a possible source of explicit negative evidence that can serve as a solution to the subset problem in the acquisition of every.

\subsubsection{Coding}

To assess the availability and generality of objections to children's statements with every, we manually examined all children's utterances in the Manchester corpus that included every (a total of 72 utterances). Direct objection from caregivers to every-statements by the child within 5 lines of subsequent discourse was coded as a correction.

\subsubsection{Results}

Only one example with an objection was found, given in (18). In this example, the parent's response would have been false if every had an existential meaning.

(18) Context: Pretend-play with a train. Child pretends to get on the train with sister and dad, but states that "Mommy left behind".

a. Child: that one Nina [sister].

Child: and that one Daddy.

Child: and Mummy left behind.

Mother: oh.

$\cdots$

Child: look.

Child: everybody's on the train.

b. Mother: not everybody.

Dominic, Age 2;7 


\subsubsection{Summary: explicit negative feedback}

The extremely low frequency of every in our sample of child speech makes it difficult to estimate the availability of explicit negative feedback in general. At the same time, there is an independent reason to be unsurprised by the observed scarcity of direct objections to children's utterances with every, which is that there is evidence that children seem to have acquired the correct meaning of every by the time they start using it (Philip 2011 and references cited therein). We will tentatively conclude that direct objections do not provide systematic evidence against the existential meaning, with the caveat that the sample size in this case was small and potentially unrepresentative of child speech.

\subsection{Informative truth-conditional evidence}

In addition to explicit negative feedback, the input may also provide evidence of a truth-conditional nature against a weaker meaning for every. The subset problem arises because in many situations a universal claim is compatible with a weaker, existential claim, but there are situations where this is not the case, either because the entailment patterns are different or because the existential claim violates some semantic constraint. We counted as potentially useful truth-conditional evidence downward-entailing and non-monotonic environments, as well as "existential-rejecting" environmentsenvironments where the existential quantifier cannot be used for semantic reasons, including exceptive phrases, NPIs, and the adverbials almost and nearly. If caregivers systematically produce every in such environments and children know enough about the properties of such environments to exploit this fact, then truth-conditional evidence alone may allow the child to solve this particular instantiation of the subset problem.

\subsubsection{Coding}

To evaluate the availability and systematicity of truth-conditional evidence against the existential meaning for every, we inspected caregiver utterances for uses of every (i) in the scope of negation (not, no, never), with and without other intervening operators, and in the scope of fewer than $n$ (downward-entailing environments), and (ii) in the scope of exactly and between $m$ and $n$ (non-monotonic environments). We also considered three types of existential-rejecting environments: exceptive phrases involving but, NPIs like any and ever in the restrictor of every, and the scalar modifiers almost and nearly. We discuss each of these candidates in detail below, before presenting the corpus results.

\subsubsection{Downward-entailing environments}

Gualmini and Schwarz (2009) observed that input with downward-entailing environments may provide a general solution to the subset problem in semantics. Since downward-entailing environments reverse entailment relations, replacing the universal meaning of every with an existential meaning results in a stronger statement, and 
stronger statements may be too strong to be consistent with usages of every in the input. Consider the example in (19), where the downward-entailing operator is the propositional negation it's not the case that. Under negation, the statement with the existential quantifier (here pronounced as any) entails the statement with the universal quantifier.

(19) (a) $\rightarrow$ (b)

a. It's not the case that any girl ran.

b. It's not the case that every girl ran.

Since replacing the universal quantifier with the existential results in a stronger meaning, we can construct scenarios in which (19b) is true but (19a) is false. An example of a relevant scenario is given in (20). In this scenario, assigning an existential meaning to every results in falsity. If such scenarios are available in the child's input, they could provide the child with direct evidence against the existential hypothesis for every.

(20) Context: Three out of five girls ran.

It's not the case that every girl ran.

Of course, propositional negation of the form it's not the case that is typically not available in child-language corpora. The more common form is not, which makes the picture more complicated. We now turn to not as our first example of a potentially informative downward-entailing operator.

3.2.2.1 Negation Consider the following scenario, where every is interpreted in the scope of not (key words boldfaced):

(21) Context: The child is asking to put more Mercurochrome (an antiseptic) on her cut, even though some had been used on a preceding day. The mother rejects the request because Mercurochrome should not be used on a daily basis.

a. Child: Mercurocrome on it.

b. Mother: you got Mercurochrome on it. you only put a little bit. you don't put it on every day, you know. it'll go away.

If the quantifier pronounced as every takes scope under negation, it cannot have the existential meaning. Given the existential meaning, the mother's utterance would mean that Mercurochrome should never be used, which is too strong in this context, given that Mercurochrome has been used recently. But every could have the existential meaning if it scopes over negation, in which case the resulting meaning would be equivalent to a universal under negation. This equivalence can be illustrated using the following unambiguous paraphrases:

(22) a. 'It's not the case that one puts Mercurochrome on every day.'

b. 'Some day is such that one doesn't put Mercurochrome on then.'

If mechanisms for inverse scope are available to the child, and in particular mechanisms that allow an existential to take inverse scope over negation, examples like (21) provide 
no definitive basis for the child to rule out the existential meaning for every. ${ }^{7}$ The mother's utterance is compatible with a grammar in which every has the existential meaning if this grammar allows the existential to scope over negation. To be able to rule out the existential meaning using downward-entailing environments, we need to consider other downward-entailing environments, where no scope possibility for the existential would be equivalent to the intended meaning. We turn to such environments next.

3.2.2.2 Downward-entailing environments that break equivalence Consider another downward-entailing operator, the determiner no:

(23) No girl read every book.

In this case, both surface and inverse scopes with the existential meaning are logically stronger than surface scope with the universal meaning. The two scopes for the existential can be unambiguously paraphrased as follows:

(24) 'No girl read any book.' (surface scope)

(25) 'Some book is such that no girl read it.' (inverse scope)

We can construct hypothetical scenarios in which the existential meaning would be too strong under either scope, while the surface-universal scope would be true. For example, suppose that there are three books and three girls, and the relation between girls and books they have read is as in (26).

(26) Context:

a. books $=\left\{b_{1}, b_{2}, b_{3}\right\}$

b. $\operatorname{girls}=\left\{g_{1}, g_{2}, g_{3}\right\}$

c. $g_{1}$ only read $b_{1}, g_{2}$ only read $b_{2}, g_{3}$ only read $b_{3}$

In this context, the utterance in (23) would only be true under the universal meaning for every but not under the existential meaning (i.e., both (24) and (25) would be false). This means that the use of every alongside no in such contexts would constitute informative input for the child.

Equivalence could also break down when another operator intervenes between negation and the quantifier. A modal is such an operator. Consider the following utterance:

(27) Context: Two parents and their child are ready to have dessert. There is a cookie, a cake, and a pudding on the table.

a. Child: Which dessert is for me?

b. Mother: You can eat the cookie, the cake, or the pudding, but you can't eat everything.

\footnotetext{
7 It has been claimed that children have a preference for surface-scope readings for sentences containing a quantifier and negation (Musolino 1998; Musolino and Lidz 2003), but also that children are indeed able to access inverse scope readings at the same ages (Musolino and Lidz 2006; Gualmini et al. 2008).
} 
The mother's utterance in bold is multiply ambiguous. To see why, let us represent its three operators as follows: $n o t=\neg$, can $=\diamond$, every $=\forall$. Let us also assume that the relative scope between negation and can is fixed such that $\neg$ out-scopes $\diamond(\neg>\diamond)$, as is the case in English. This leaves three potential meanings, where (a) is the intended meaning:

$$
\begin{aligned}
& \text { a. } \neg>\diamond>\forall \\
& \text { 'It is not allowed that you eat everything.' } \\
& \text { b. } \neg>\forall>\diamond
\end{aligned}
$$

'There is a thing that you are not allowed to eat.'

c. $\forall>\neg>\diamond$

'Everything is such that you are not allowed to eat it.' (i.e., you cannot eat anything)

Meanings (b) and (c) are stronger than (a) and are incompatible with the context, since the mother explicitly states that the child can pick any of the desserts to eat. If the universal meaning is replaced with the existential, we get the following three corresponding interpretations:

a. $\neg>\diamond>\exists$

'Everything is such that you are not allowed to eat it.' (i.e., you cannot eat anything)

b. $\neg>\exists>\diamond$

'Everything is such that you are not allowed to eat it.' (i.e., you cannot eat anything)

c. $\exists>\neg>\diamond$

'There is a thing that you are not allowed to eat.'

Given the existential meaning for every, none of the three interpretations are compatible with the mother's utterance in (27). If children are exposed to utterances with negation, a modal, and every in a context that rules out all stronger interpretations given the existential meaning, then children could use such utterances to rule out the existential as a meaning for every. We therefore further coded all negative environments for the presence or absence of an intervening modal, including existential as well as universal modals.

\subsubsection{Non-monotonic environments}

Non-monotonic environments are environments that are neither downward-entailing nor upward-entailing. For non-monotonic environments, it is possible to construct scenarios in which every scope for the existential quantifier would be false. Consider the non-monotonic operator exactly and a context in which there are three books, four girls, and the relation between girls and books that they read is as in (30).

(30) Context:

a. books $=\left\{b_{1}, b_{2}, b_{3}\right\}$ 
b. girls $=\left\{g_{1}, g_{2}, g_{3}, g_{4}\right\}$

c. $g_{1}$ and $g_{2}$ each read $b_{1}, b_{2}$, and $b_{3} ; g_{3} \operatorname{read} b_{1}$ and $b_{2} ; g_{4}$ read $b_{2}$ and $b_{3}$

In this context, the utterance in (31) is true under the universal meaning for every but, as we will now see, not under the existential meaning.

(31) Exactly two girls read every book.

The two scopes for the existential relative to exactly can be unambiguously paraphrased as follows:

(32) 'Exactly two girls are such that they read some book.' (surface scope)

(33) 'Some book is such that exactly two girls read it.' (inverse scope)

Surface existential scope is false in the context in (30) because more than two girls read books, and inverse scope is false because each book was read by at least three girls.

Like downward-entailing environments, non-monotonic environments have the property that they can provide a general solution to the subset problem.

\subsubsection{Existential-rejecting environments}

There are several environments where every can be used but an existential quantifier cannot. Here we consider such environments as further potential kinds of informative input.

3.2.4.1 NPI-licensing The first environment involves negative polarity items (NPIs) like any and ever, which are licensed in the restrictor of every. In contrast to every, existential quantifiers do not license NPIs in their restrictor:

(34) a. Every movie that I have ever watched was good.

b. *Some movie that I have ever watched was good.

Theories of NPI-licensing typically attribute this contrast to a semantic difference between every and the existential quantifier (Ladusaw 1980). Namely, every is downward-entailing in its restrictor but the existential quantifier is not. If these theories are correct, then inputs with an NPI in the restrictor of every could provide the child with direct evidence against the existential meaning for every, provided the child already has knowledge of NPI-licensing. ${ }^{8}$

\footnotetext{
8 There is evidence that children as young as 2 treat any as an NPI and seem to understand where it is licensed (Tieu 2015; Gualmini 2004), and that 4-year-olds are sensitive to the fact that every is downward-entailing in its restrictor (Gualmini et al. 2003; Crain et al. 2004). 
3.2.4.2 Almost and nearly The words almost and nearly are scalar modifiers whose semantics makes them incompatible with existential arguments, as illustrated in (35). ${ }^{9}$ Since these words are incompatible with an existential argument, they can provide informative input for the child when used with every. This would be true if the child has knowledge of the universal requirement of almost and nearly before acquiring the meaning of every.

(35) a. Almost/nearly every student arrived.

b. *Almost/*nearly some student arrived.

3.2.4.3 Exceptive but The distribution of the exceptive expression but obeys a universality restriction (von Fintel 1993), illustrated in (36). If the child has knowledge of this restriction before having acquired the meaning of every, then utterances like (36a) would be informative.

(36) a. Every girl but Michelle read a book.

b. *Some girl but Michelle read a book.

\subsubsection{Results}

3.2.5.1 Downward-entailing environments Every occurred in downward-entailing environments 77 times (11.7\%, CIs[5.2\%-23.9\%]) in caregiver utterances in the Manchester corpus. Figure 3 displays the proportion of downward-entailing environments in caregiver utterances split by child.

All 77 occurrences involved every and not. Though these environments are reliably present in caregiver speech, we saw above that usages of every with not are unhelpful for rejecting the existential hypothesis for every, because inverse scope with the existential is logically equivalent to surface scope with the universal. We therefore looked for cases where this equivalence is broken: cases where every is in the scope of $n o$ and cases where a modal operator intervenes between negation and every. There were no occurrences of every scoping under no in the corpora. The same result of zero occurrences was obtained for fewer than $n$, which has a similar behavior to no. Among the 77 occurrences of every with negation, 16 (2.14\%) occurrences also had an intervening modal, but none appeared in an informative context that rules out the existential meaning. An example is the following occurrence:

(37) Context: Playtime; the child is refusing to share his toys with his mother. Whenever she asks if she can play with a certain toy, the child says that he will play with that toy.

a. Mother: so if I play with this yellow car that's alright then?

b. Child: I play yellow car.

c. Mother: you can't play with everything.

Dominic, Age 2;3

\footnotetext{
${ }^{9}$ For theories of the difference between universal and existential complements to almost and nearly, see Sadock (1981), Sevi (1998), Penka (2006) and Amaral and Del Prete (2010).
} 


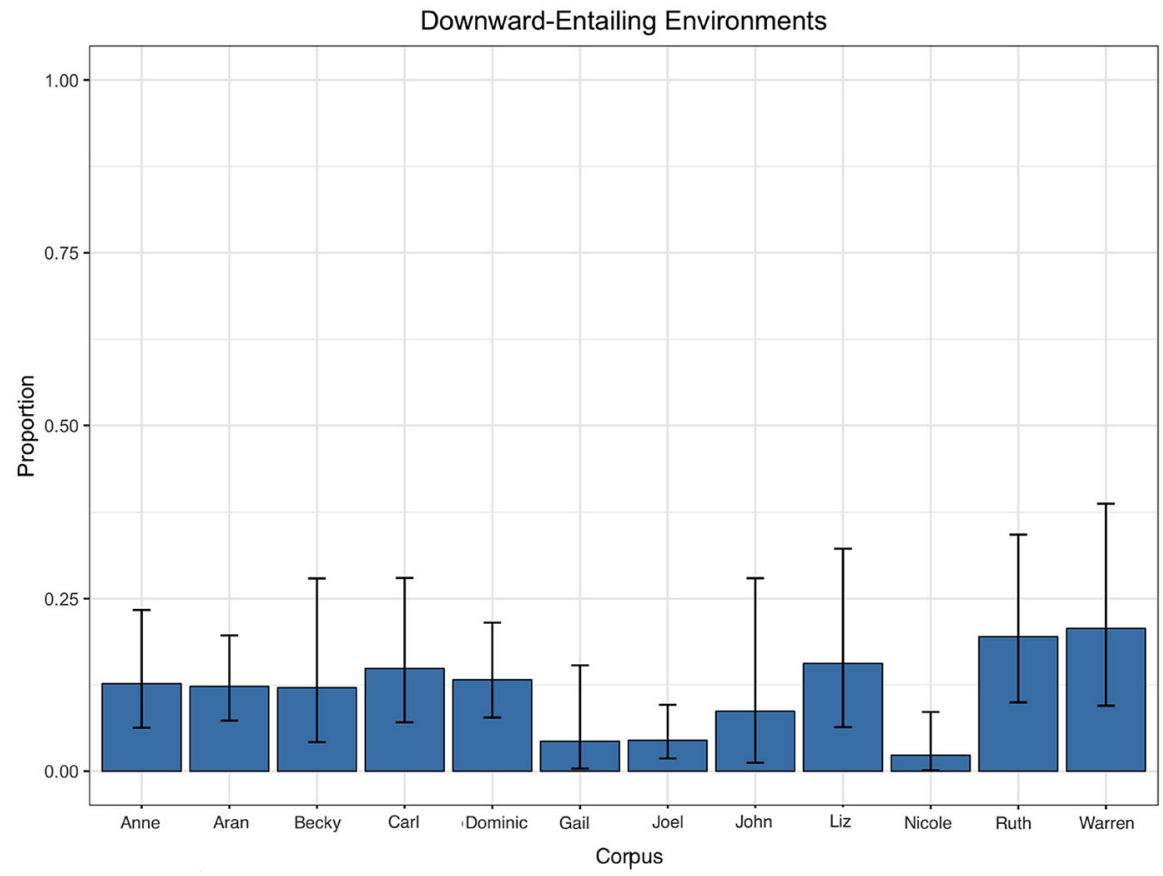

Fig. 3 Proportions and 95\% binomial confidence intervals of downward-entailing environments in caregiver utterances in the Manchester corpus

If every has an existential meaning and it takes widest scope over negation and the modal, the resulting interpretation is the one in (38). This interpretation can be true in the context: it could be that there is a certain car that the child is not allowed to play with, and this car is the yellow car. (This utterance would not be a cooperative utterance, but recall that in this section we are only considering the possibility that utterances with the existential are true. The contribution of pragmatics will be discussed separately in Sect. 3.3.) Note that the context in (37) is different from the context in the earlier, informative example of the same shape in (27), because in (37) the context does not say that the child can play with each of the toys.

(38) $\exists>\neg>\diamond$

'There is a thing that you are not allowed to play with.'

Our conclusion is that, considering truth conditions alone, downward-entailing environments did not provide unambiguous evidence against the existential meaning for every.

3.2.5.2 Non-monotonic environments To assess the availability of informative nonmonotonic environments in the input, we searched the corpora for occurrences of the non-monotonic operators exactly and between $m$ and $n$. There were no occurrences of these operators (0/746), indicating that informative non-monotonic environments with 
these operators do not in fact provide the child with a solution to the subset problem for every.

3.2.5.3 Existential-rejecting environments We examined the corpus for occurrences of the three types of existential-rejecting environments discussed above. These included the NPIs any and ever in the restrictor of every, occurrences of the expressions nearly and almost modifying every, and exceptives of the form every A but $x$. We found 13 such cases overall, distributed among 5 of the 12 corpora examined.

We found two informative examples of the NPIs any and ever in the restrictor of every, one of which is given below.

(39) mummy's fallen off every single horse she's ever got on. Joel, Age 2;6

There were five occurrences in the corpus of almost every or nearly every.

(40) we've tried playing with almost everything today, haven't we? Aran, Age 2;5

Finally, there were six examples like (41) in the corpus with but and every, four of which were uttered by the same parent.

(41) I think that's everything but the dolly. Nicole, Age 2;3

Overall, $1.75 \%$ (CIs[0-11.4\%]) of caregiver utterances in the corpus included every in potentially informative existential-rejecting environments.

\subsubsection{Summary: truth-conditional evidence}

We have seen that different sources of truth-conditional evidence that could provide the child with evidence against the existential meaning for every were either infrequent or consistent with weaker meanings. Considering downward-entailing environments, non-monotonic environments, NPI-licensing, almost, nearly, and the exceptive but, there were a total of 13 informative utterances $(1.75 \%)$ overall. ${ }^{10}$ On the basis of this result, and assuming the null theory of acquisition in (16), we conclude that the input is not rich enough to systematically rule out the existential meaning using truthconditional evidence alone.

\subsection{Informative pragmatic evidence}

In the previous section, we asked whether replacing the universal meaning of every with an existential meaning resulted in a false utterance or in a violation of some semantic constraint. Here we ask a different question: whether replacing the universal

\footnotetext{
10 In addition, these 13 informative utterances came from a subset of five corpora, meaning that the remaining seven children were not exposed to any informative utterances of this sort.
} 
with an existential results in an odd utterance that violates some pragmatic constraint. We first consider utterances where replacement with an existential results in oddness due to a violation of Grice's (1967/1975) Maxim of Quantity. We will see that such utterances are commonly available in the input. However, we will point out that the child's ability to use such utterances to eliminate the existential hypothesis for every depends on certain open questions concerning implicature computation and alternatives that are actively debated in the literature. We then turn to oddness due to violations of two different pragmatic constraints: a constraint on the non-redundancy of assertions and a constraint on the non-vacuity of questions. Both are constraints against triviality: that one must not proffer information that is already common ground and that one must not ask a question whose answer is already common ground. In both cases, the input is abundant with utterances that become odd under an existential meaning for every. If the child is able to use these constraints, she could infer that every does not have the existential meaning and thus avoid this instance of the subset problem in the acquisition of every. This, in turn, would mean that the null theory of acquisition in (16) could be maintained and that additional learning principles are not needed to acquire the universal meaning of every over the existential alternative.

\subsubsection{Coding}

To assess the availability of pragmatic evidence ruling out the existential hypothesis for every, we manually examined each caregiver utterance with every in context. We looked at 50 lines of the preceding discourse and 5 lines of the following dialogue in order to establish a discourse context against which the utterance was evaluated. All utterances were coded independently by the two authors and later checked for intercoder agreement $(\kappa=.90)$. For each utterance for which there was disagreement, agreement was later established after considering a greater portion of the preceding discourse.

We coded each utterance for whether or not it would violate one of three pragmatic principles if the universal meaning of every were replaced with an existential one: the Maxim of Quantity, Non-redundancy of Assertions, and Non-vacuity of Questions. In each case, we asked whether, given the context, the child has grounds to believe that a weaker, existential meaning would render an utterance with every uncooperative in the relevant sense (the three principles and our coding criteria for each principle are discussed in the following sections). If so, we coded the utterance as potentially informative on the basis of one of the three constraints.

We discuss each candidate in detail below, before presenting our results. 


\subsubsection{Maxim of Quantity}

Consider the following hypothetical exchange:

(42) Context: The parent encourages the child to eat as many cookies as possible. There are three cookies in the jar.

a. Parent: Let's see if you can finish eating the cookies in the jar.

b. (The child eats all three cookies.)

c. Parent: Good job, you ate every cookie.

Given the context, the parent's utterance in (42c) would be odd under an existential meaning for every:

(43) Parent: \#Good job, you ate a/some cookie.

Even though our focus in this paper is on the existential alternative to every, we note that this context makes odd a broader family of sensible alternative denotations including, for example, most:

(44) Parent: \#Good job, you ate most cookies.

Can the child reason pragmatically about scenarios like (42) to eliminate the existential hypothesis for every? To answer this question, we need to look more closely into theories of the oddness of (43). Here we discuss a theory that relies on the NeoGricean Maxim of Quantity (NGMQ; Horn 1972; Horn and Ward 2004; Sauerland 2004; Spector 2006, among others):

(45) NGMQ: A speaker shouldn't utter $\phi$ if there is a stronger alternative $\psi$ that the speaker believes is true.

In order for the child to use NGMQ to infer that (43) would be odd, at least three conditions must be met:

(46) a. The child can use NGMQ.

b. The child must believe that her parent believes that the universal statement is correct (i.e., that she ate all the cookies).

c. The set of alternatives for (43) must include an utterance in which the existential is replaced with an element that leads to a stronger meaning.

Condition (a) can be met if the child is at a stage where she can use NGMQ. Condition (b) can be met if the child is at a stage where she can hold beliefs regarding other people's beliefs. In the scenario in (42), for example, the child sees directly that her parents sees that she ate all the cookies. Condition (c), however, depends on the set of alternatives for the existential that are available to the child before she has acquired the meaning of every. The literature on implicatures has offered two competing theories regarding the set of available alternatives, and the difference between the two theories 
matters. ${ }^{11}$ On one theory, alternatives are available to a speaker regardless of whether she has lexicalized them (Deal 2011; Buccola et al. 2018). For example, the universal quantifier would be an alternative to the existential even in languages that do not have a word for the universal. If this theory is correct, the English-learning child should have access to the universal quantifier as an alternative to other quantifiers even before acquiring the meaning of every, and condition (c) could be satisfied. In other words, if alternatives like the universal quantifier are available to the child before lexicalization, the child could use scenarios like (42) to rule out the existential hypothesis for every, and this instance of the subset problem could disappear. ${ }^{12}$

On other theories, however, morphemes cannot serve as alternatives unless they have been lexicalized (Katzir 2007; Fox and Katzir 2011). If this is the case, then in order for condition (c) to be satisfied, the child should have already lexicalized a meaning that is stronger than the existential quantifier, and acquiring any such meaning should have posed a version of the subset problem. In other words, on the assumption that alternatives are not accessible before they have been lexicalized, scenarios like (42) would be uninformative unless the child had already solved an instance of the subset problem and correctly rejected the existential meaning in favor of some stronger meaning. Since this is the very learning problem that we are interested in here, it would be unreasonable to assume that the child had already independently solved an instance of the subset problem. We are left to conclude that oddness due to NGMQ provides a general strategy for rejecting the weaker existential meaning if the following conditions are met:

(47) Conditions for using NGMQ as a solution to the subset problem:

1. The child can use NGMQ.

2. The child can hold beliefs regarding other speakers' beliefs.

3. Stronger alternatives to the existential quantifier (e.g., the universal quantifier) are available regardless of lexicalization.

\subsubsection{Assertions and non-redundancy}

Sentences asserted in a conversation are meant to contribute new information; redundant assertions are to be avoided. An influential theory of what counts as redundant comes from Stalnaker $(1974,1978,1999,2002)$. On this view, the basic role that assertive speech acts play in language use is to update the body of shared beliefs of the interlocutors-the common ground - by adding the content of what is asserted

\footnotetext{
${ }^{11}$ Here we make the simplifying assumption that the alternatives used for the computation of oddness are the same alternatives used for the computation of implicatures. This need not be the case, but as far as we can tell, our conclusions will not change if the two sets turn out to be distinct: our discussion could remain the same except that "alternatives" would refer only to alternatives used for the computation of oddness, as long as there is no evidence regarding those alternatives that conflicts with our claims.

12 Previous acquisition research suggests that children are more accepting of sentences that violate the Maxim of Quantity in comprehension tasks (Noveck 2001 and many others since). More recently, it has been proposed that children's difficulties stem from their inability to retrieve the relevant lexical alternatives (Barner et al. 2011; Singh et al. 2016). If this proposal is on the right track, then scenarios like (42) may not be helpful for the child even if the requisite alternatives are in principle available without lexicalization.
} 
to what was already shared information (see also von Fintel 2008). Stalnaker (1978) introduces a pragmatic principle stating that assertion of sentence $S$ with respect to context $c$ is felicitous only if it results in a non-trivial update of $c$. One way for triviality to obtain is if the information is already part of the conversational common ground, i.e. it is redundant. A speaker making a speech act is therefore expected to adhere to the principle in (48).

(48) Principle of Non-Redundancy: An assertion is infelicitous if the asserted proposition is already common ground. (paraphrased from Stalnaker (1999), p. 88)

Against this background, consider the hypothetical exchange in (49).

(49) Context: The child's older brother is in the kitchen eating cookies from a jar that contains 10 cookies. Every few minutes, the parent updates the child (who is in a different room) about the total number of cookies her brother has eaten so far.

a. Parent: Your brother ate two cookies.

b. (The parent goes to the kitchen and then returns with another update.)

c. Parent: Your brother ate every cookie.

In the given context, the parent's assertion in (c) would be odd if every were an existential quantifier:

(50) Parent: \#Your brother ate a/some cookie.

Notice that differently from the exchange in (42), here the child does not know whether the statement with every is correct, so the Maxim of Quantity is unhelpful in accounting for the oddness of (50). Instead, according to the non-redundancy principle in (48), the utterance in (50) is odd since it repeats information known to both interlocutors (the brother's eating of some cookie) and cannot change the common ground of the conversation. If the child can use this principle before she has acquired the meaning of every, she could use scenarios like (49) to rule out the existential meaning for every.

\subsubsection{Questions}

Questions are another possible source of pragmatic evidence against the existential meaning. ${ }^{13}$ Consider a context in which somebody has arrived (cf. (13)). In this context, the question in (51a) would be natural but the question in (51b) would be odd.

(51) Context: somebody has arrived.

a. Is everybody here?

b. \#Is anybody here?

The oddness of (51b) is presumably due to a pragmatic constraint like the following (different formulations of this constraint are assumed in Groenendijk and Stokhof 1984, Roberts 1996, Büring 2003, Fox 2018, among others):

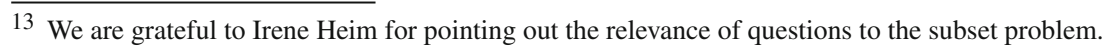




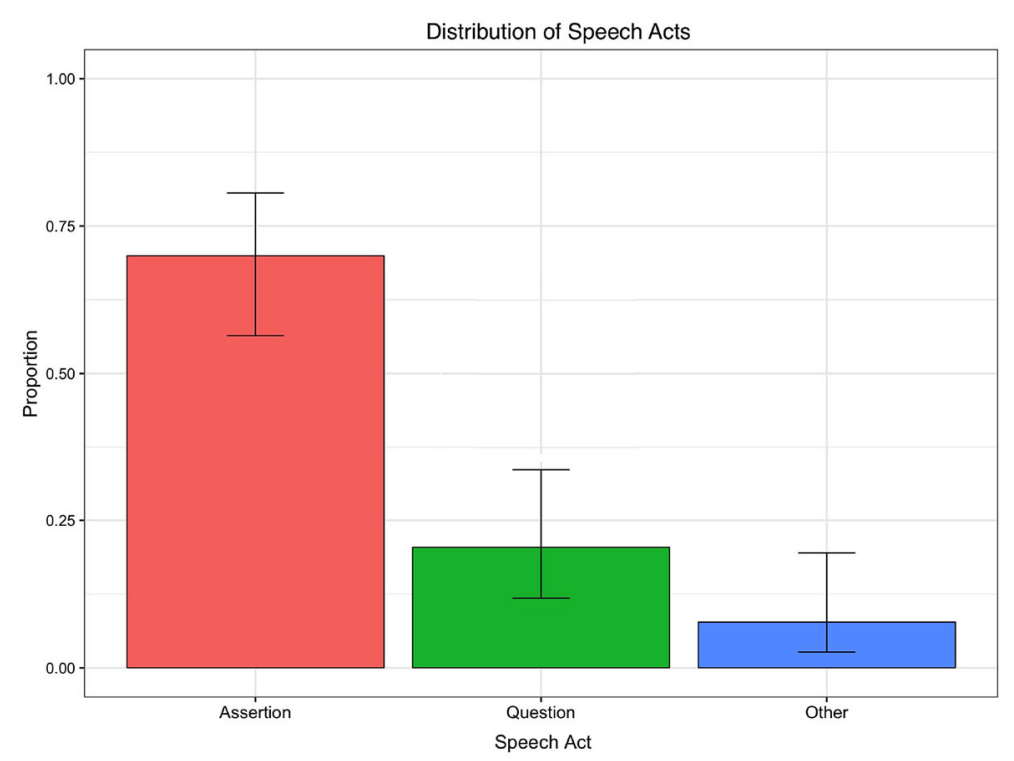

Fig. 4 Proportion and 95\% CIs of declaratives and questions in caregiver utterances with every

(52) Do not ask a question whose answer is common ground.

According to this constraint, the question in (51b) is odd in the context, assuming that the speaker and the addressee already know that at least one person has arrived. If the child can use (52) before she has acquired the meaning of every, she could use scenarios like (51) to reject the existential meaning for every. Given (52), questions are a helpful source for rejecting the weaker existential meaning, since the answer to the question with the existential is weak enough to be entailed by the context.

\subsubsection{Results}

We examine declaratives and questions separately, as they are governed by distinct pragmatic conditions. There were a total of 528 assertions and 161 questions. The proportion of each type of speech act in caregiver utterances with every is displayed in Fig. 4. The 'Other' category includes imperatives and uncategorizable utterances (e.g., one word utterances).

3.3.5.1 Declaratives Maxim of Quantity To address the question of whether the Maxim of Quantity could be helpful in eliminating an existential meaning hypothesis for every, we manually examined all declarative utterances with every in context. We were conservative in what we considered to be informative: an utterance with every was coded as informative only if the context provided a clear indication that the child has grounds to believe that the speaker/caregiver believes that the universal statement is true. So, given an utterance of the form Every toy is broken, if the context makes it likely that the domain of quantification of every is a set of toys present and visible to both parent and child in the situation, we counted the sentence as informative; if 
the domain of quantification was not deducible from the transcripts alone, we did not count the sentence as informative. Our results thus likely under-estimate the amount of informative evidence of this sort that the child is privy to.

Only 26 out of 528 declarative utterances with every were informative in this sense (an example is given in (53)). Of course, as per the discussion in Sect. 3.3.2, whether the Maxim of Quantity offers a solution to the subset problem is contingent on what will turn out to be the right theory of alternatives, so we will leave it as a conditional solution that must await further verification.

(53) Mother: shall we put all the food bits back in here?

Child: bread.

Mother: I think that's supposed to be meat.

Child: it looks similar to bread.

Child: here you go.

Mother: thank you.

Child: here you go.

Mother: thank you.

Mother: everything (is) in the basket now.

John, Age 2;1

Non-redundancy To assess the availability of scenarios like (49), we searched the corpus for usages of every in declaratives, once again examining each usage in context. We considered an assertion to constitute evidence against the existential meaning whenever the context provided an indication that the existential variant of the assertion introduces information already known to both the parent and child, as well as an indication that the child has grounds to believe that the parent knows that information. There were 94 usages of every where the context provided these indications (an example is provided in (54)). This constituted $17.7 \%$ of declaratives (CIs[10.1-36.8\%]) and $12.6 \%$ of the every utterances in total (CIs[6.4-26.1\%]).

(54) Child: Andy want this? [a kiss]

Child: just that for Andy.

(Inferable: The child kisses Andy.)

Mother: make him laugh with all these kisses.

Child: give me a kiss.

Mother: want to kiss me?

(Inferable: The child kisses the mother.)

Mother: oh, he's kissing everybody.

Gail, Age 2;6

3.3.5.2 Questions To assess whether non-vacuity conditions on question-asking could systematically provide evidence against an existential meaning for every, we manually examined in context all questions in the corpus that included every; for each case, we asked whether the following two conditions were met:

1. There was a clear indication that the context entails the answer to the existential counterpart of the question (i.e., a minimal variant of the question in which every is replaced with the existential quantifier). 
2. There was a clear indication that the context does not entail the answer to the question as uttered (with every). ${ }^{14}$

Of the total caregiver utterances with every (746), 161 were questions, and 37 (22.9\%, CIs[9.8-56.2\%]) of these were informative according to our criteria (an example is given in (55)), a total of 4.9\% (CIs[2.08-17.4\%)] informative questions of the overall input.

(55) Mother: now what do you need?

Mother: eggs.

Mother: there we go.

Mother: have you got everything you want now?

Child: yeah.

Nicole, Age 2;1

\subsubsection{Summary: pragmatic evidence}

Figure 5 summarizes the proportions of caregiver utterances that were informative with respect to the three sources of pragmatic evidence discussed in this section.

Informative pragmatic evidence for rejecting the existential meaning for every was systematically available in the corpus: considering the non-triviality of assertions and questions (and not counting the Maxim of Quantity), 17.5\% of the usages of every (133/746) had the property that replacing every with the existential quantifier would have led to a violation of a pragmatic constraint. Given the systematicity of the evidence available to the child against the existential meaning, we conclude that the child does not face an instance of the subset problem of acquisition in this case: the null theory of acquisition in (16), which cannot select between multiple hypotheses compatible with the input, is sufficient to acquire the meaning of every despite the presence of the existential meaning in the hypothesis space. We can therefore conclude that principles proposed in the literature that might in principle solve the subset problem with every, such as the Principle of Contrast, the Semantic Subset Principle, the likelihood component of Bayesian learning, and the $|D: G|$ component of Minimum Description Length, are redundant in this case. This conclusion presupposes that pragmatic principles (such as the Maxim of Quantity and principles of non-redundancy) are needed to account for adult speakers' behavior (e.g., felicity judgments) even after the learning process has been completed and the child has converged on the adult grammar. Such pragmatic principles are thus needed independently of any learning principles. Once these pragmatic principles are fixed, and given that they can eliminate this instance of the subset problem in the acquisition of every, additional principles that achieve the same goal are redundant. Even if the learning principles mentioned above receive

\footnotetext{
14 This measure was taken to ensure that the relevant question is in fact information-seeking. Child-directed speech often includes questions that are used by the caregiver for reasons other than eliciting information from the child (e.g., to check that the child is attending to the same things that the caregiver is). The constraint in (52) is inactive in such situations. If the child has grounds to believe that a question is not information-seeking (for example, if the context makes it clear that the caregiver knows the answer to the question), then (52) should play no role in their pragmatic reasoning even if the first condition is met.
} 


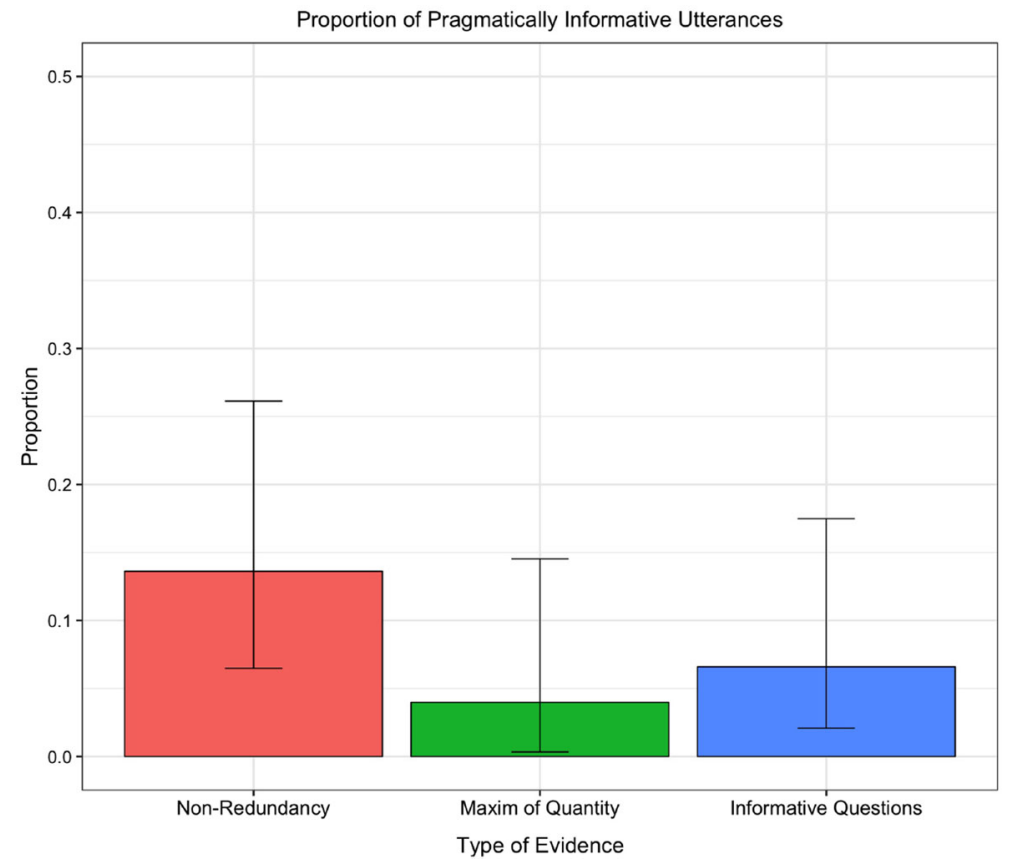

Fig. 5 Proportion and 95\% CIs of pragmatically informative caregiver utterances with every

empirical support elsewhere, we find it an interesting conclusion they are not needed to favor the universal meaning over the existential meaning in the acquisition of every, despite having been proposed to solve problems of a similar nature.

\section{Logically stronger alternatives and the superset problem}

In this section we discuss potential instances of the superset problem in the acquisition of every, the mirror image of the subset problem. As mentioned in Sect. 1, the superset problem arises whenever logically stronger meaning candidates for every are compatible with the child's input.

Consider the quantifier $\llbracket$ every $_{>2} \rrbracket$ in $(56 \mathrm{~b})$ as an alternative to our assumed meaning

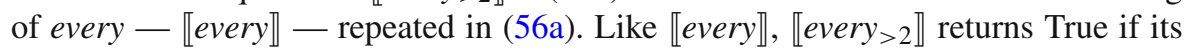

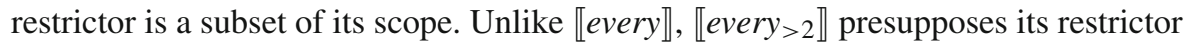
to have a cardinality greater than two, a stronger requirement than the presupposition

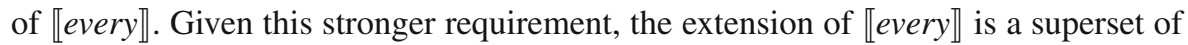
the extension of $\llbracket$ every $>2 \rrbracket$, as indicated in (57).
a. $\llbracket$ every $\rrbracket=\lambda P:|P|>0 . \lambda Q . P \subseteq Q$
b. $\llbracket$ every $>2 \rrbracket=\lambda P:|P|>2 . \lambda Q . P \subseteq Q$

$$
\llbracket \text { every }>2 \rrbracket \subset \llbracket \text { every }
$$


The correct English meaning of every in (56a) is difficult to distinguish empirically from the alternative in (56b). The difficulty arises since usages of English every often lead to an inference that its restrictor has more than two elements. The first two examples in (58) illustrate the oddness of using every when the cardinality of the domain is exactly one or two (Sauerland 2008).

(58) a. \#Every nose of Michelle's is runny.

b. \#Every cheek of Bill's is rosy.

c. Every finger of Mary's is long.

According to Sauerland (2003, 2008), Percus (2006), and Chemla (2008), among others, the oddness of every in (58a) and (58b) arises not because of a lexical presupposition along the lines of «every $>2 \rrbracket$, but due to a competition of every with the presuppositionally stronger the (which carries a uniqueness presupposition) and the presuppositionally stronger both (which carries a duality presupposition), respectively. The competition is due to a pragmatic principle, Maximize Presupposition! (Heim 1991), which forces speakers to choose from a set of competitors the sentence that carries the strongest presuppositions satisfied in the context. On the assumption that cooperative speakers adhere to this pragmatic principle, the choice of a competitor with weaker (or no) presuppositions would be odd. Using (58b) as an example, the speaker's choice of every is odd since it only presupposes that Bill has cheeks, while the alternative with both carries the stronger presupposition that Bill has exactly two cheeks (which is trivially satisfied given our common knowledge about the duality of human cheeks).

There are two types of evidence that the non-uniqueness and non-duality inferences are not part of the semantics of every (the following discussion is based on Sauerland 2008). The first is that unlike lexically encoded presuppositions, non-uniqueness and non-duality are easily cancellable. As illustrated by (59), every can be used even when the speaker is ignorant about the cardinality of the domain of quantification. The acceptability of (59) would be surprising under 【every $>2 \rrbracket$, which encodes non-

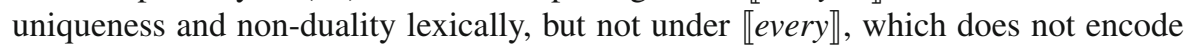
them.

(59) I don't know if Michelle has more than two cats or not, but I bet that every cat of hers is happy.

The second type of evidence that non-uniqueness and non-duality are not part of the semantics of every is that these inferences behave differently from lexically-encoded presuppositions in embedded contexts. Under various theories of presupposition projection (e.g., Karttunen and Peters 1979; Heim 1983; Schlenker 2008), universally quantified sentences of the form Every $A B$ presuppose that every element in the restrictor satisfies the presuppositions in the nuclear scope. The duality presupposition of both in the nuclear scope behaves as predicted: in (60a), we take it that every candidate wrote exactly two papers. The non-uniqueness and non-duality inferences of every in the nuclear scope do not pattern analogously: (60b) is compatible with situations where some candidates have written exactly one or two papers. The felicity 
of (60b) in such contexts is surprising if the lower every (underlined) means «every $>2 \rrbracket$, which encodes non-uniqueness and non-duality semantically.

(60) a. Every candidate submitted both papers of hers.

b. Every candidate submitted every paper of hers.

Semanticists have access to utterances like (59) and (60b) and can use them to reject

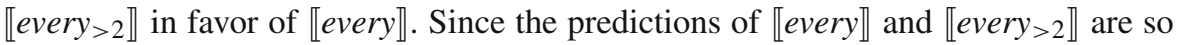
subtly divergent, (59) and (60b) had to be carefully constructed to properly tease the two meanings apart. For the child, of course, things are different. Informative evidence against the subset meaning 【every $>2 \rrbracket$ requires special circumstances for it to occur in the child's input. For evidence like (59) to occur in the input, the caregiver would need to signal their ignorance about the cardinality of the restrictor of every. For evidence like (60b) to occur in the input, every would need to be embedded in the scope of another quantifier and in a specific context; for example, the utterance in (60b) would be informative only if the child knew that some candidates have written just one or two papers.

\subsection{Coding}

To assess the availability of evidence against «every $>2 \rrbracket$ in the child's input, we searched the corpora for occurrences of examples like (59) and (60b). To our knowledge, no other types of evidence have been proposed in the literature to distinguish between the two meanings in (56a) and (56b). For examples like (59), we examined the usages of every in context to determine whether the caregiver's ignorance about the cardinality of the restrictor of every was signaled in any way. For examples like (60b), we marked all occurrences of every alongside another quantifier which the non-uniqueness and non-duality inferences of every do not project out of (every, always, usually, normally, exactly, between $m$ and $n$, etc.). For each example we found, we evaluated whether the child is provided with the right context to determine that the restrictor of every can include exactly one or two elements.

\subsection{Results}

We found no utterances that are inconsistent with «every $>2 \rrbracket$. There were no occurrences of every where the caregiver signaled ignorance regarding the size of the restrictor. There were only 6 occurrences of every in the scope of another potentially informative quantifier, but none appeared in a context that makes the usage of

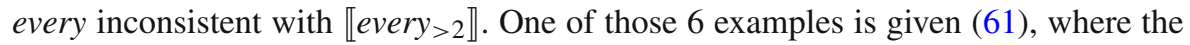
other quantifier is as usual. The mother mentions multiple occasions in which the child threw objects on the floor, but there is no indication that one of those occasions involved exactly one or two objects being thrown. Without such indication, it is possible that each occasion involved more than two objects being thrown by the child, which, in turn, would make the utterance in (61) consistent with 【every $>2 \rrbracket$. 
(61) Because you chuck everything on the floor as usual, don't you?

Dominic, Age 2;8

\subsection{Discussion}

Our finding suggests that systematic evidence against «every $>2 \rrbracket$ is not available in the child's input. This means that the child may as well conclude on the basis of her input that every requires its restrictor to have more than two elements. This is the state of affairs discussed in Sect. 1: the child is faced with two competing hypotheses

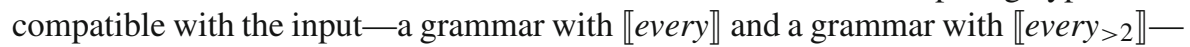
and has to choose between them. In this case, the child makes an inductive leap to conclude that every allows any non-empty restrictors, rather than only restrictors with more than two elements.

The same inductive problem for the child can be created using quantifiers other

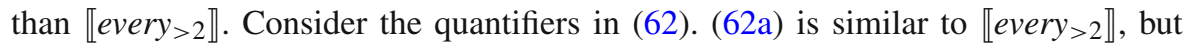
the restriction on its domain is an additional conjunct in the assertive component of the meaning rather than a presupposition. For (62b), assume that the child has been exposed to usages of every with restrictors of sizes that do not exceed some finite number $n$. (62b) adds $n$ as an upper bound on the possible size of the restrictor of every. (62c) is even more restrictive, and simply records the sizes of observed restrictors without making any size-based generalization. Each example in (62) adds a pointless complication to the meaning of every that renders it more restrictive, in a way that keeps the quantifiers compatible with usages of every in the input.

$$
\begin{array}{ll}
\text { a. } & \lambda P \lambda Q . P \subseteq Q \wedge|P|>2 \\
\text { b. } & \lambda P \lambda Q . P \subseteq Q \wedge(2<|P|<n) \\
\text { c. } & \lambda P \lambda Q . P \subseteq Q \wedge(|P|=3 \vee|P|=5 \vee|P|=6 \vee \ldots)
\end{array}
$$

The inductive problem posed by «every $>2 \rrbracket$ and by the quantifiers in (62) is similar to an inductive problem that has been discussed in the philosophical literature on induction, albeit in a different context than child language acquisition. Goodman (1955) observed that usages of the English predicate green, whose meaning is given in (63), are also consistent with the meaning of the predicate grue in (64) (which we have adapted to our notation), assuming that $1 / 1 / 2029$ is some future time. Goodman's puzzle, which he referred to as the "new riddle of induction", concerned the inductive leap from one's past observations of green to the meaning in (63), given that the alternative in (64) is also consistent with all past usages of green. Goodman noted that considerations of simplicity can license the inductive step from (64) to (63),

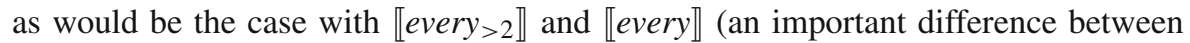
the two examples is that (64) and (63) are not ordered by strength, so the inductive problem posed by grue is not a superset problem).

(63) $\llbracket$ green $\rrbracket=\lambda x \cdot x$ is green

(64) $\llbracket$ grue $\rrbracket=\lambda x . x$ is green if observed before $1 / 1 / 2029$ or blue if observed later 
Similarly, Kripke (1982) proposed the mathematical operator quus $(\bigoplus)$ defined in (65) as an alternative to addition. The operator quus behaves like the regular addition operator ' + ' for arguments up to some finite number (57 in Kripke's example), but beyond that number it always returns 5. Kripke's question was what licenses the inference that addition behaves like ' + ' and not like quus (or similar alternatives with a number higher than 57), given that our exposure to addition is consistent with both.

$$
\text { (65) } x \bigoplus y= \begin{cases}x+y & \text { if } x, y<57 \\ 5 & \text { otherwise }\end{cases}
$$

In both Goodman's and Kripke's examples, the challenge is to generalize beyond the observed data. Our result that the child's input does not provide evidence against 【every $>2 \rrbracket$ as an alternative meaning to every indicates that the child faces a version of Goodman's and Kripke's problem in the acquisition of every. Assuming that «every $>2 \rrbracket$ is consistent with the child's input, the challenge is to generalize the meaning of every to restrictors of any positive size. Of course, differently from Goodman and Kripke, our goal is to understand the consequences of this inductive problem for child language acquisition. In what follows, we discuss a few possible conclusions of interest that arise from our result, though we will leave a definitive conclusion for future research.

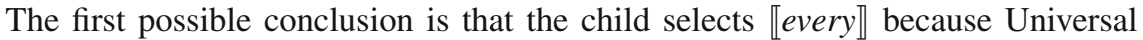
Grammar (UG) does not make the quantifiers in (56b) and (62) available. Stated differently, the child's hypothesis space is restricted so as to exclude (56b) and (62) as possible quantifiers, as well as any other quantifiers with the same extensions. This possibility, while correctly addressing the inductive problem, would require very specific constraints on the child's hypothesis space. The quantifiers in (56b) and (62) obey familiar universal constraints on quantifiers, such as Conservativity, Isomorphy, and Extension (Barwise and Cooper 1981; Keenan and Stavi 1986; van Benthem 1986; Peters et al. 2006), and their denotation is similar to other lexicalized meanings. For example, the denotation in (56b) is almost identical to the denotation of both, given in (66). Constraints on the child's hypothesis space that exclude (56b) would have to be stated specifically enough so as not to also exclude the attested (66). Of course, whether quantifiers like (56b) and (62) are in the child's hypothesis space is an empirical question, which could be tested experimentally (see Hunter and Lidz 2012 for a concrete experimental paradigm, though see de Villiers and Spenader 2019 for a criticism of that paradigm).

$$
\llbracket b o t h \rrbracket=\lambda P:|P|=2 . \lambda Q \cdot P \subseteq Q
$$

An alternative conclusion to draw from the inductive problem is that the quantifiers in (56b) and (62) are part of the child's hypothesis space but the null theory of acquisition in (16) is insufficient, because it says nothing about learning when more than one hypothesis is compatible with the input (modulo noise). An alternative to (16) could be a more complex theory of learning according to which the child is biased

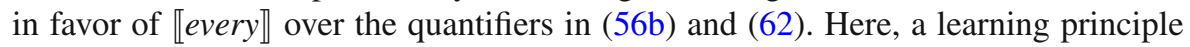
such as the Semantic Subset Principle (Crain et al. 1994), which pushes the child towards subset meanings, would lead the child astray if used by itself, since the child generalizes to a superset meaning (see Musolino et al. 2019 for another critique of the 
Semantic Subset Principle). As mentioned above, Goodman (1955) noted that pressure for generalization can come from a bias for simplicity. In generative linguistics, the idea that simplicity could be used as a learning criterion for the child was explored in Halle (1962), Chomsky (1965), and Chomsky and Halle (1968) for both phonology and syntax. Simplicity-based learning criteria have later been proposed for a variety of language-learning tasks by Berwick (1982), de Marcken (1996), Goldsmith (2001), Chater and Vitányi (2007), Rasin and Katzir (2016), and many others.

Can a simplicity bias address the superset problem in the acquisition of every? Since simplicity-based comparisons depend on the language of description, the answer depends on how UG allows meaning representations of quantifiers to be written. To illustrate this dependency, consider again the two competing meanings for every, repeated in (67). In this case, simplicity will be of little help: the two meanings are roughly equivalent in their complexity, so a child equipped with a bias for simplicity (say, a bias for representations with fewer symbols) will have little incentive to choose one meaning over the other and may as well select the incorrect meaning 【every $>2 \rrbracket$.

$$
\begin{aligned}
& \text { a. } \llbracket \text { every } \rrbracket=\lambda P:|P|>0 . \lambda Q . P \subseteq Q \\
& \text { b. } \llbracket \text { every }>2 \rrbracket=\lambda P:|P|>2 . \lambda Q . P \subseteq Q
\end{aligned}
$$

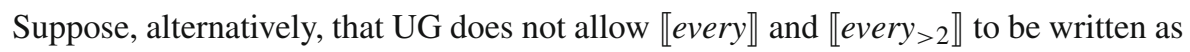
in (67) — for example, because of a property like the following:

(68) Hypothetical Property of UG: The symbol ' $>$ ' is not a primitive that can be used in meaning representations of quantifiers.

If the symbol ' $>$ ' cannot be used, the competition is no longer between the representations in (67) but between alternative representations in the child's hypothesis space that are extensionally equivalent to them. A different way of writing the same quantifiers without the symbol ' $>$ ' is to use the "not equal" sign ' $\neq$ ' and a sequence of conjunctions, as in (69).

$$
\begin{aligned}
& \text { a. } \llbracket \text { every’ }^{\prime} \rrbracket=\lambda P: P \neq \emptyset . \lambda Q . P \subseteq Q \\
& \text { b. } \llbracket \text { every' }^{\prime} \rrbracket=\lambda P: P \neq \emptyset \wedge|P| \neq 1 \wedge|P| \neq 2 . \lambda Q . P \subseteq Q
\end{aligned}
$$

The two representations now meaningfully differ in their complexity. Assuming the property of UG in (68), a child guided by a preference for simpler representations (e.g., representations with fewer symbols) will now correctly choose «every'】over 【every' $>2 \rrbracket$. If UG does not make available other representations that are extensionally

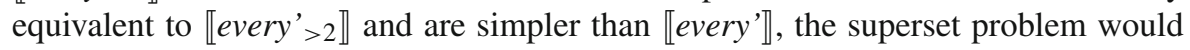
be solved.

In sum, we have illustrated how a theory of UG with the property in (68) might correctly account for children's choice of the universal quantifier over the alternative when combined with a learning bias for simplicity. Under theories of UG without the property in (68), children's acquisition of every given the alternative in (67) remains a mystery. This discussion illustrates a possible way in which our finding regarding the superset problem in the acquisition of every can be used to draw inferences regarding UG, and specifically regarding how representations of quantifier meanings can be written. See Piantadosi et al. (2016) and Katzir et al. (2020) for further discussion of how 
simplicity-based learning criteria can help tease apart the predictions of extensionally equivalent representations of quantifier meanings.

As mentioned above, our brief discussion is not meant to provide a definitive conclusion regarding the consequences for language acquisition of the inductive problem presented in this section. Instead, we aimed to illustrate how that inductive problem can lead to concrete conclusions regarding acquisition that we find interesting, such as possible restrictions on the child's hypothesis space, choices regarding the primitives available to the child in constructing meaning representations, or inductive biases such as simplicity. We leave a more systematic exploration of these possibilities for future research.

\section{Conclusion}

Our findings suggest an asymmetry between the subset problem and the superset problem in the acquisition of every. We first discussed the subset problem and showed that the input for semantic learning is rich enough to eliminate overly general hypotheses about the meaning of every. Specifically, we saw that if every had an existential meaning instead of a universal, a significant percentage of input utterances with every in the corpus $(17.5 \%)$ would have been too weak to be cooperative utterances and would have violated pragmatic constraints on assertions and questions. This finding means that the input in semantics is qualitatively different from the input in syntax and phonology-domains in which systematic negative evidence against overly-general hypotheses is unavailable and in which the null theory of language acquisition (according to which no induction is involved in learning acquisition) has been rejected. We then discussed some instances of the superset problem in the acquisition of every. We showed that as opposed to overly general hypotheses, usages of every in the child's input contain no evidence against some overly specific hypotheses about the meaning

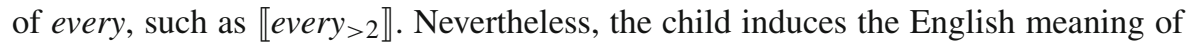
every. We suggested directions for future research that can use this inductive problem to draw conclusions regarding the hypothesis space of quantifier meanings and the primitive symbols that can be used in writing quantifier representations.

While this paper has focused on the acquisition of every, our findings are relevant for semantic acquisition beyond every. Our finding regarding the role of pragmatic constraints in solving the subset problem is general: weaker hypotheses about word meanings can be too weak to be cooperative, which could make such hypotheses incompatible with the child's input. Our discussion suggests a general recipe for examining this question in cases other than every by considering weaker alternative meanings and examining the systematicity of evidence against them in the input. Our exploration of the superset problem can also be extended to cases other than every, as strictly more complex meaning representations like «every $>2 \rrbracket$ can generally result in stronger meanings that overfit the observed data. If such meanings are not too strong to be systematically inconsistent with the input, the result is a case of non-trivial induction to the more general meaning performed by the child. We hope that further exploration of the relationship between the semantic hypothesis space and the child's 
input will help advance our understanding of semantic acquisition in general, and of UG in particular.

Funding Open Access funding enabled and organized by Projekt DEAL.

Open Access This article is licensed under a Creative Commons Attribution 4.0 International License, which permits use, sharing, adaptation, distribution and reproduction in any medium or format, as long as you give appropriate credit to the original author(s) and the source, provide a link to the Creative Commons licence, and indicate if changes were made. The images or other third party material in this article are included in the article's Creative Commons licence, unless indicated otherwise in a credit line to the material. If material is not included in the article's Creative Commons licence and your intended use is not permitted by statutory regulation or exceeds the permitted use, you will need to obtain permission directly from the copyright holder. To view a copy of this licence, visit http://creativecommons.org/licenses/by/4.0/.

\section{References}

Amaral, Patrícia, and Fabio Del Prete. 2010. Approximating the limit: The interaction between quasi 'almost' and some temporal connectives in Italian. Linguistics and Philosophy 33: 51-115.

Barner, D., N. Brooks, and A. Bale. 2011. Accessing the unsaid: The role of scalar alternatives in children's pragmatic inference. Cognition 118: 84.

Barwise, Jon, and Robin Cooper. 1981. Generalized quantifiers and natural language. Linguistics and Philosophy 4: 159-219.

Berwick, Robert C. 1982. Locality principles and the acquisition of syntactic knowledge. PhD dissertation, MIT.

Berwick, Robert C. 1985. The acquisition of syntactic knowledge. Cambridge, MA: MIT Press.

Brown, R., and C. Hanlon. 1970. Derivational complexity and the order of acquisition of child speech. In Cognition and the development of language, ed. J.R. Hayes, 11-53. New York: Wiley.

Buccola, Brian, Manuel Križ, and Emmanuel Chemla. 2018. Conceptual alternatives: Competition in language and beyond. Ms., ENS Paris. Available on LingBuzz: https://ling.auf.net/lingbuzz/003208. (unpublished $\mathrm{ms}$.).

Büring, Daniel. 2003. On d-trees, beans, and b-accents. Linguistics and Philosophy 26: 511-545.

Chater, Nick, and Paul Vitányi. 2007. 'Ideal learning' of natural language: Positive results about learning from positive evidence. Journal of Mathematical Psychology 51: 135-163.

Chemla, Emmanuel. 2008. An epistemic step for anti-presuppositions. Journal of Semantics 25: 141-173.

Chomsky, Noam. 1965. Aspects of the theory of syntax. Cambridge, MA: MIT Press.

Chomsky, Noam, and Morris Halle. 1968. The sound pattern of English. New York: Harper and Row.

Chomsky, Noam, and Howard Lasnik. 1977. Filters and control. Linguistic Inquiry 8: 425-504.

Clark, Eve V. 1987. The principle of contrast: A constraint on language acquisition. Mechanisms of Language Acquisition 1: 33.

Crain, Stephen, Weijia Ni, and Laura Conway. 1994. Learning, parsing and modularity. In Perspectives on sentence processing, ed. Charles Clifton et al., 443-467. Hillsdale, NJ: Lawrence Erlbaum.

Crain, Stephen, Luisa Meroni, and Utako Minai. 2004. If everybody knows, then every child knows. In LOT Occasional Series, vol. 3, ed. J. van Kampen and S. Baauw, 127-138. Amsterdam: LOT.

de Marcken, Carl. 1996. Unsupervised language acquisition. PhD dissertation, MIT.

de Villiers, Jill, and Jennifer Spenader. 2019. Are conservative quantifiers easier to learn? Experiments with novel quantifiers. In Proceedings of the 22nd Amsterdam Colloquium, ed. Julian J. Schloeder, Dean McHugh, and Floris Roelofsen, 504-512.

Deal, Amy Rose. 2011. Modals without scales. Language 87: 559-585.

Dell, François. 1981. On the learnability of optional phonological rules. Linguistic Inquiry 12: 31-37.

Fox, Danny. 2018. Partition by exhaustification: Comments on Dayal 1996. In Proceedings of Sinn und Bedeutung, vol. 22, ed. Uli Sauerland and Stephanie Solt, 403-434. Berlin: ZAS.

Fox, Danny, and Roni Katzir. 2011. On the characterization of alternatives. Natural Language Semantics 19: 87-107.

Gleitman, Lila. 1990. The structural sources of verb meanings. Language Acquisition 1: 3-55. 
Goldsmith, John. 2001. Unsupervised learning of the morphology of a natural language. Computational Linguistics 27: 153-198.

Goodman, Nelson. 1955. Fact, fiction, and forecast. Cambridge, MA: Harvard University Press.

Grice, Paul. 1967/1975. Logic and conversation. In Syntax and semantics 3: Speech acts, ed. P. Cole and J. L. Morgan, 41-58. New York: Academic Press.

Groenendijk, Jeroen, and Martin Stokhof. 1984. On the semantics of questions and the pragmatics of answers. In Varieties offormal semantics, ed. Fred Landman and Frank Veltman, 143-170. Dordrecht: Foris.

Gualmini, Andrea. 2004. Some knowledge children don't lack. Linguistics 42: 957-982.

Gualmini, Andrea, and Bernhard Schwarz. 2009. Solving learnability problems in the acquisition of semantics. Journal of Semantics 26: 185-215.

Gualmini, Andrea, Sarah Hulsey, Valentine Hacquard, and Danny Fox. 2008. The question-answer requirement for scope assignment. Natural Language Semantics 16: 205.

Gualmini, Andrea, Luisa Meroni, and Stephen Crain. 2003. An asymmetric universal in child language. In Proceedings of Sinn und Bedeutung, vol. 7, ed. Matthias Weisgerber, 136-148. Konstanz: Arbeitspapiere des Fachbereichs Sprachwissenschaft.

Hacquard, Valentine, and Jeffrey Lidz. 2019. Children's attitude problems: Bootstrapping verb meaning from syntax and pragmatics. Mind \& Language 34: 73-96.

Halle, Morris. 1962. Phonology in generative grammar. Word 18: 54-72.

Heim, Irene. 1983. On the projection problem for presuppositions. In Proceedings of WCCFL 2, ed. D. Flickinger, 114-125. Stanford, CA: Stanford University Press.

Heim, Irene. 1991. Artikel und Definitheit. In Semantik: Ein internationales Handbuch der zeitgenössischen Forschung, ed. A. von Stechow and D. Wunderlich. Berlin: De Gruyter.

Horn, Laurence. 1972. On the semantic properties of logical operators in English. UCLA dissertation. Distributed by Indiana University Linguistics Club, Bloomington.

Horn, Laurence R. and Gregory L. Ward. 2004. The handbook of pragmatics. Hoboken: Wiley Online Library.

Hunter, Tim, and Jeffrey Lidz. 2012. Conservativity and learnability of determiners. Journal of Semantics 30 (3): 315-334.

Karttunen, Lauri, and Stanley Peters. 1979. Conventional implicature. In Syntax and semantics 11: Presupposition, ed. Oh Choon-Kyu and David Dineen, 1-56. New York: Academic Press.

Katzir, Roni. 2007. Structurally-defined alternatives. Linguistics and Philosophy 30: 669-690.

Katzir, Roni, Nur Lan, and Noa Peled. 2020. A note on the representation and learning of quantificational determiners. In Proceedings of Sinn und Bedeutung 24, ed. Michael Franke et al. https:// semanticsarchive.net/Archive/mZhNDA4Y/.

Keenan, Edward L., and Jonathan Stavi. 1986. A semantic characterization of natural language determiners. Linguistics and Philosophy 9: 253-326.

Kripke, Saul A. 1982. Wittgenstein on rules and private language: An elementary exposition. Cambridge, MA: Harvard University Press.

Ladusaw, William A. 1980. Polarity sensitivity as inherent scope relations. New York: Garland.

Landau, Barbara, Linda B. Smith, and Susan S. Jones. 1988. The importance of shape in early lexical learning. Cognitive development 3: 299-321.

Landman, Fred. 2004. Indefinites and the type of sets. London: Blackwell.

MacWhinney, Brian. 2000. The CHILDES project: The database, vol. 2. Hove: Psychology Press.

Marcus, Gary F. 1993. Negative evidence in language acquisition. Cognition 46: 53-85.

Markman, Ellen M. 1990. Constraints children place on word meanings. Cognitive Science 14: 57-77.

Markman, Ellen M., Judith L. Wasow, and Mikkel B. Hansen. 2003. Use of the mutual exclusivity assumption by young word learners. Cognitive Psychology 47: 241-275.

Musolino, Julien. 1998. Universal Grammar and the acquisition of semantic knowledge. PhD dissertation, University of Maryland.

Musolino, Julien, and Jeffrey Lidz. 2003. The scope of isomorphism: Turning adults into children. Language Acquisition 11: 277-291.

Musolino, Julien, and Jeffrey Lidz. 2006. Why children aren't universally successful with quantification. Linguistics 44: 817-852.

Musolino, Julien, Kelsey Laity d'Agostino, and Steve Piantadosi. 2019. Why we should abandon the Semantic Subset Principle. Language Learning and Development 15: 32-46. 
Noveck, Ira A. 2001. When children are more logical than adults: Experimental investigations of scalar implicature. Cognition 78: 165-188.

Penka, Doris. 2006. Almost there: The meaning of almost. In Proceedings of Sinn und Bedeutung, vol. 10, ed. Christian Ebert and Cornelia Endriss, 275-286. Berlin: ZAS.

Percus, Orin. 2006. Antipresuppositions. In Theoretical and empirical studies of reference and anaphora: Toward the establishment of generative grammar as an empirical science, ed. A. Ueyama, 52-73. Tokyo: Japan Society for the Promotion of Science.

Perlmutter, David. 1971. Deep and surface structure constraints in syntax. New York: Holt, Rinehart and Winston.

Peters, Stanley, and Dag Westerståhl. 2006. Quantifiers in language and logic. Oxford: Oxford University Press.

Philip, William. 2011. Acquiring knowledge of universal quantification. In Handbook of generative approaches to language acquisition, ed. Jill de Villiers and Tom Roeper, 351-394. Dordrecht: Springer.

Piantadosi, Steven T. and Joshua B. Tenenbaum. 2012. Modeling the acquisition of quantifier semantics: A case study in function word learnability. Manuscript, Rochester University, MIT, and Stanford University.

Piantadosi, Steven T., Joshua B. Tenenbaum, and Noah D. Goodman. 2016. The logical primitives of thought: Empirical foundations for compositional cognitive models. Psychological Review 123: 392-424.

Prince, Alan, and Bruce Tesar. 2004. Learning phonotactic distributions. In Constraints in phonological acquisition, ed. René Kager, Joe Pater, and Wim Zonneveld, 245-291. Cambridge: Cambridge University Press.

Rasin, Ezer, and Roni Katzir. 2016. On evaluation metrics in Optimality Theory. Linguistic Inquiry 47 (2): 235-282.

Roberts, Craige. 1996. Information structure in discourse: Towards an integrated formal theory of pragmatics. In Papers in semantics (OSU working papers in linguistics 49), ed. Jae-Hak Yoon and Andreas Kathol, 91-136. Columbus: The Ohio State University.

Sadock, Jerrold M. 1981. 'Almost'. In Radical pragmatics, ed. Peter Cole, 257-271. New York: Academic Press.

Sauerland, Uli. 2003. A new semantics for number. In Proceedings of SALT 13, ed. Robert B. Young and Yuping Zhou, 258-275. Ithaca, NY: CLC.

Sauerland, Uli. 2004. Scalar implicatures in complex sentences. Linguistics and Philosophy 27: 367-391.

Sauerland, Uli. 2008. Implicated presuppositions. In The discourse potential of underspecified structures, ed. Anita Steube, 581-600. Berlin: De Gruyter.

Schlenker, Philippe. 2008. Be articulate! A pragmatic theory of presupposition projection. Theoretical Linguistics 34: 157-212.

Sevi, Aldo. 1998. A semantics for 'almost' and 'barely'. Master's thesis, Tel-Aviv University.

Singh, Raj, Ken Wexler, Andrea Astle-Rahim, Deepthi Kamawar, and Danny Fox. 2016. Children interpret disjunction as conjunction: Consequences for theories of implicature and child development. Natural Language Semantics 24: 305-352.

Spector, Benjamin. 2006. Aspects de la pragmatique des opérateurs logiques. PhD dissertation, Université Paris 7.

Stalnaker, Robert. 1974. Pragmatic presupposition. In Semantics and philosophy, ed. Milton Munitz and Peter Unger, 197-213. New York: New York University Press.

Stalnaker, Robert. 1978. Assertion. In Syntax and semantics 9: Pragmatics, ed. Peter Cole, 315-332. New York: Academic Press.

Stalnaker, Robert. 1999. Context and content: Essays on intentionality in speech and thought. Oxford: Oxford University Press.

Stalnaker, Robert. 2002. Common ground. Linguistics and Philosophy 25: 701-721.

Theakston, Anna L., Elena V.M. Lieven, Julian M. Pine, and Caroline F. Rowland. 2001. The role of performance limitations in the acquisition of verb-argument structure: An alternative account. Journal of Child Language 28: 127-152.

Tieu, Lyn. 2015. Input vs. output in the acquisition of negative polarity: The curious case of any. Language, Cognition, and Mind 1: 327-343.

Tomasello, Michael and Daniel Stahl. 2004. Sampling children's spontaneous speech: How much is enough? Journal of Child Language 41: 101-121.

van Benthem, Johan. 1986. Essays in logical semantics. Dordrecht: Reidel.

von Fintel, Kai. 1993. Exceptive constructions. Natural Language Semantics 1: 123-148. 
von Fintel, Kai. 2008. What is presupposition accommodation, again? Philosophical Perspectives 22: 137170.

Wexler, Kenneth, and Rita M. Manzini. 1987. Parameters and learnability in binding theory. In Parameter setting, ed. Thomas Roeper and Edwin Williams, 41-76. Dordrecht: Reidel.

Xu, F., and J.B. Tenenbaum. 2007. Word learning as Bayesian inference. Psychological Review 114: 245272.

Publisher's Note Springer Nature remains neutral with regard to jurisdictional claims in published maps and institutional affiliations. 